\title{
KNOWLEDGE AND AWARENESS REGARDING ANTIBIOTIC PROPHYLAXIS FOR INFECTIVE ENDOCARDITIS AMONG UNDERGRADUATE DENTAL STUDENTS
}

\author{
SANTHOSH KUMAR MP'*, SNEHA ${ }^{2}$ \\ ${ }^{1}$ Department of Oral and Maxillofacial Surgery, Saveetha Dental College and Hospital, Chennai, Tamil Nadu, India. ${ }^{2}$ Department of Oral and \\ Maxillofacial Surgery, Saveetha Dental College, Chennai, Tamil Nadu, India. Email: santhoshsurgeon@gmail.com
}

Received: 10 June 2016, Revised and Accepted: 23 June 2016

\section{ABSTRACT}

Objective: To evaluate the knowledge and awareness regarding antibiotic prophylaxis for infective endocarditis (IE) among undergraduate dental students.

Methods: A validated questionnaire of 16 questions, regarding the basic knowledge and awareness about antibiotic prophylaxis for the prevention of IE, was distributed among 100 students randomly belonging to final year and internship ( $5^{\text {th }}$ year trainee) of the undergraduate dental program in Saveetha Dental College and Hospital, Saveetha University, Chennai. The data extracted were tabulated, statistically analyzed, and results obtained. Results were calculated on the basis of frequency and percentages using SPSS Version 20.0.

Results: About $73 \%$ of the students were aware of IE prophylaxis, and $40 \%$ of dental students were exposed to treating patients susceptible to IE. $56 \%$ of participants answered that amoxicillin is the first line of antibiotic for IE prophylaxis and 59\% replied $2 \mathrm{~g}$ PO $1 \mathrm{hr}$ before the appointment is the recommended regimen. $36 \%$ said that erythromycin is no longer recommended by American Heart Association for IE prophylaxis. However, only one-third of the participants knew about the cardiac conditions and dental procedures that require antibiotic prophylaxis for the prevention of IE. Furthermore, only $16 \%$ knew about the recommended dosage of clindamycin.

Conclusion: This study revealed a reasonable knowledge and awareness about IE prophylaxis among undergraduate dental students but was inadequate. Hence, this study emphasizes the need for improved education in the teaching curriculum for dental students regarding IE prophylaxis. A standard protocol regarding the training as well as preventive measures for IE should be formulated for the dental students and the knowledge acquired must be transferred into practice.

Keywords: Infective endocarditis, Prophylaxis, Antibiotics, Dental students, Knowledge.

(C) 2016 The Authors. Published by Innovare Academic Sciences Pvt Ltd. This is an open access article under the CC BY license (http://creativecommons. org/licenses/by/4. 0/) DOI: http://dx.doi.org/10.22159/ajpcr.2016.v9s2.13405

\section{INTRODUCTION}

Bacterial endocarditis (BE) or infective endocarditis (IE) is a serious infection of the heart valves and endocardium that most often is related to congenital and acquired cardiac defects. BE can commonly occur in patients with artificial heart valves. If left untreated, endocarditis can damage or destroy the heart valves and can lead to life-threatening complications. It has been shown that about $10 \%$ of IE cases occur after invasive procedures with associated bacteremia, almost commonly seen in susceptible patients [1]. The causative organism has been found to be Viridans streptococci which is involved in approximately $60 \%$ of cases of IE and dental manipulation such as extraction of teeth or scaling and root planning has been considered as a source of transient bacteremia that leads to BE [2]. Investigators have revealed an oral portal of entry in $7-20 \%$ of patients with BE [3-7].

However, the incidence of $\mathrm{BE}$ is low following dental treatments, even in patients with underlying history of cardiac conditions. Since surgical dental procedures are common and risk for cardiac diseases is on the rise, use of antibiotic prophylaxis before the start of the treatment in susceptible patients is highly recommended [8]. American Heart Association (AHA) and other committees of experts have proposed different guidelines and antibiotic prophylaxis regimens for prevention of $\mathrm{BE}$ in susceptible patients which are regularly reviewed and modified based on experimental animal models, pharmacokinetic studies, bacterial susceptibility studies, BE series, studies of procedures-related bacteremia, and the efficacy of antimicrobial prophylaxis against bacteremia [8].

The AHA has formulated 8 sets of recommendations regarding the prevention of $\mathrm{BE}$ in the 1997 guideline, followed by the latest guideline published in 2007 [9]. BE is taught to all dental students as a part of their curriculum, and it is mandatory that they be familiar with the latest AHA recommendations on prevention of BE. However several studies showed inadequate knowledge among dental students regarding BE prophylaxis and AHA guidelines for prevention of BE $[1,8,10-12]$. Studies about the knowledge of dentists concerning IE prevention showed a low level of knowledge of the current guidelines among Nigerian dentists, especially pertaining to the correct dose and time of administration [13].

Knowledge of dental students about the newest guidelines for antibiotic prophylaxis for high-risk patients in dentistry and the correct application of these guidelines in different aspects are very important for a safe dental practice. Hence, the rationale of this study is to assess the level of awareness and knowledge about IE prophylaxis among undergraduate dental students of our institution.

\section{METHODS}

A cross-sectional study was conducted during the academic year in April 2016 among the undergraduate dental students of the Saveetha Dental College, Saveetha University, Chennai. 100 students were randomly enrolled in the study including the final year and intern students. All students in the study voluntarily completed a questionnaire consisting of 16 close-ended questions. The questions in the questionnaire were designed to assess their basic knowledge and awareness regarding antibiotic prophylaxis for the prevention of IE in susceptible patients. The data from the participants were collected, statistically analyzed, and results were obtained. Data management and statistical analysis were performed using the statistical software SPSS version 20.0. Frequencies and percentages were obtained for categorical data. 


\section{RESULTS}

In our study, students were in the age group of $21-24$. About $73 \%$ of the students were aware of IE prophylaxis (Fig. 1). 52\% of students did not assess the risk factors for IE while taking case history of the patient (Fig. 2). 35\% of them replied that microorganism Actinobacillus actinomycetemcomitans is not implicated with $\mathrm{BE}$, which shows they were aware of the causative organisms of BE (Fig. 3). Only 13\% of students were aware that $\mathrm{BE}$ is more likely to occur following transient bacteremia induced by routine activities such as eating and brushing teeth, whereas responses for extraction and periodontal surgery were $37 \%$ and $36 \%$, respectively (Fig. 4). Only one-fourth of the participants correctly answered that bacteremia results from 10 to 15 minutes after invasive dental procedures (Fig. 5).

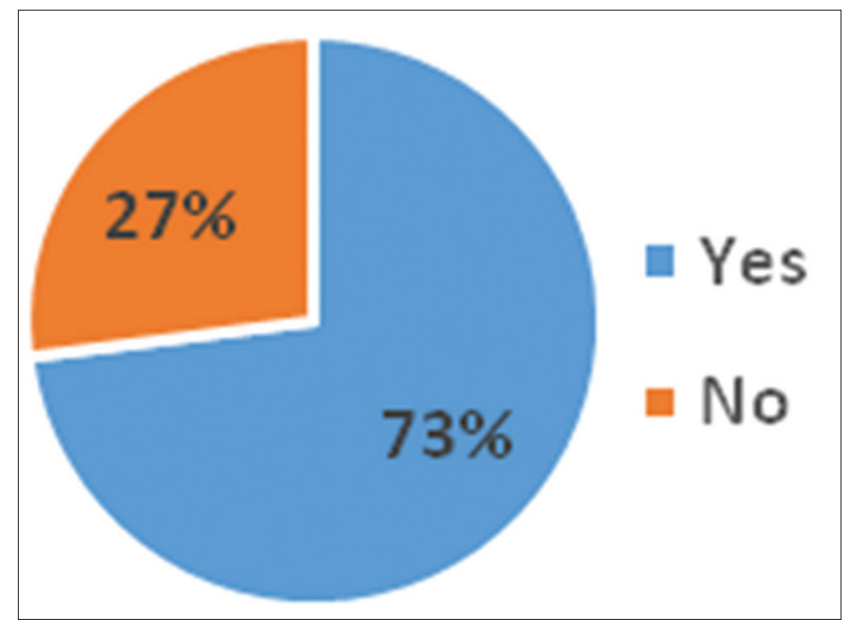

Fig. 1: Awareness about infective endocarditis prophylaxis

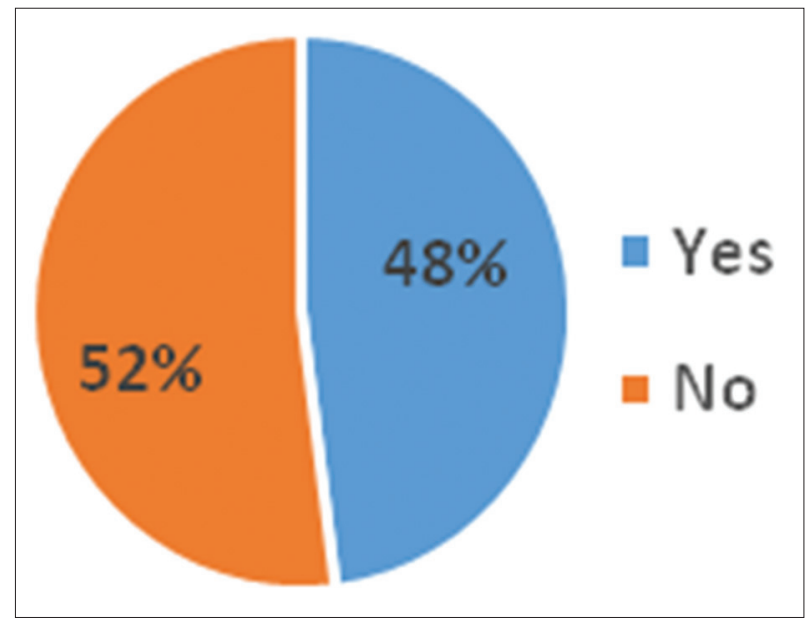

Fig. 2: Assessment of risk factors for infective endocarditis

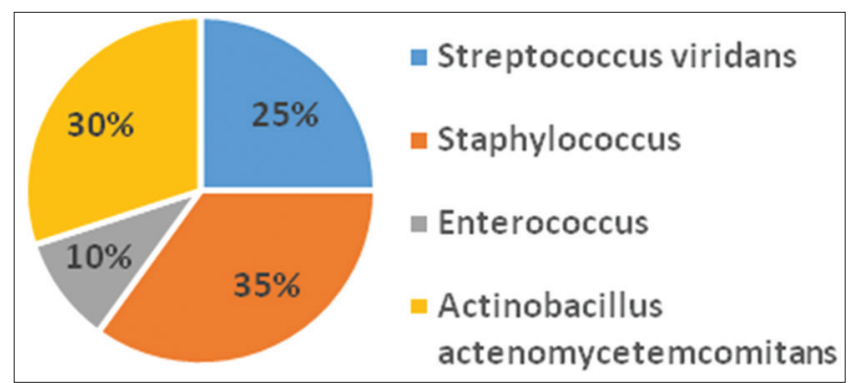

Fig. 3: Organism not implicated with bacterial endocarditis
$32 \%$ of students were aware of the cardiac conditions that require antibiotic prophylaxis against IE (Fig. 6). One-third of the participants

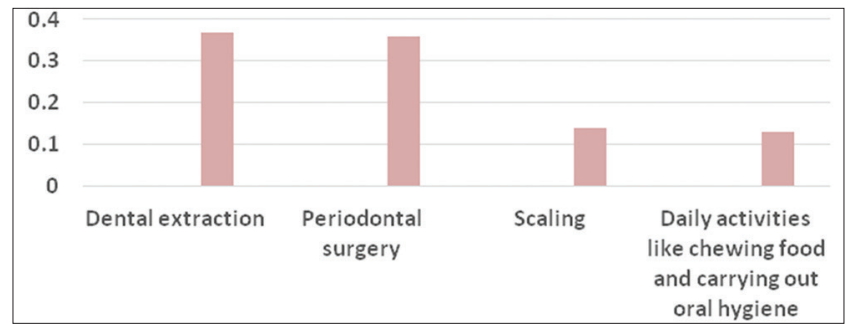

Fig. 4: Procedure which commonly induces transient bacteremia

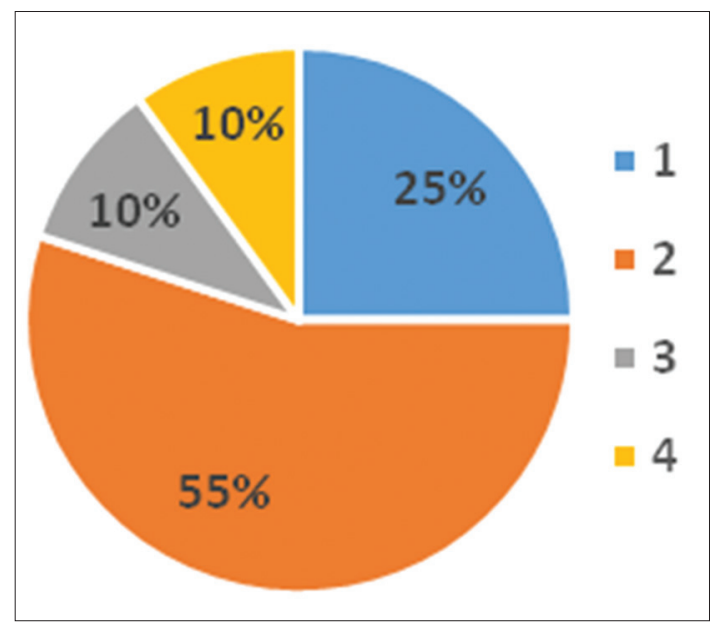

Fig. 5: Time of occurrence of bacteremia from invasive dental procedures

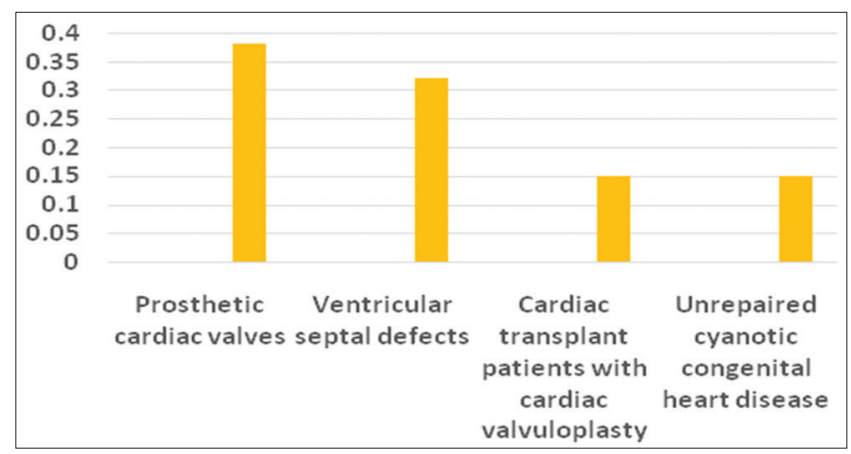

Fig. 6: Systemic condition which does not require antibiotic prophylaxis

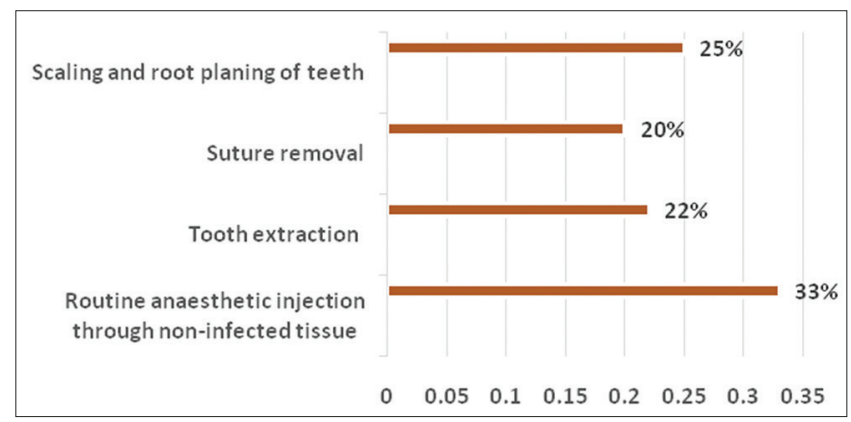

Fig. 7: Dental procedure which does not require antibiotic prophylaxis 
were aware of the dental procedures which require antibiotic prophylaxis (Fig. 7). Majority, 56\% of participants answered that amoxicillin is the drug of choice for IE prophylaxis (Fig. 8) and 59\% replied $2 \mathrm{~g}$ PO $1 \mathrm{hr}$ before the appointment is the recommended regimen (Fig. 9).

$37 \%$ of participants answered that clarithromycin is not recommended for antibiotic prophylaxis in susceptible patients, whereas $30 \%$ of students opted for penicillin V (Fig. 10). 36\% replied that erythromycin is no longer recommended by AHA for IE prophylaxis (Fig. 11). 50\% of students answered clindamycin as an alternative drug for patients who are allergic to penicillin, whereas $7 \%$ replied all of the drugs mentioned can be prescribed (Fig. 12). Majority, 47\% of participants were aware that effective prophylaxis is possible if the patient is medicated anytime up to 2 hrs from the time of induced bacteremia (Fig. 13)

$50 \%$ of them said the dosage of clindamycin is $300 \mathrm{mg}$, whereas $16 \%$ answered $600 \mathrm{mg}$ as the recommended dosage (Fig. 14). 54\% students replied that less number of patients were recommended for IE prophylaxis according to 2007 AHA guidelines (Fig. 15). 40\%

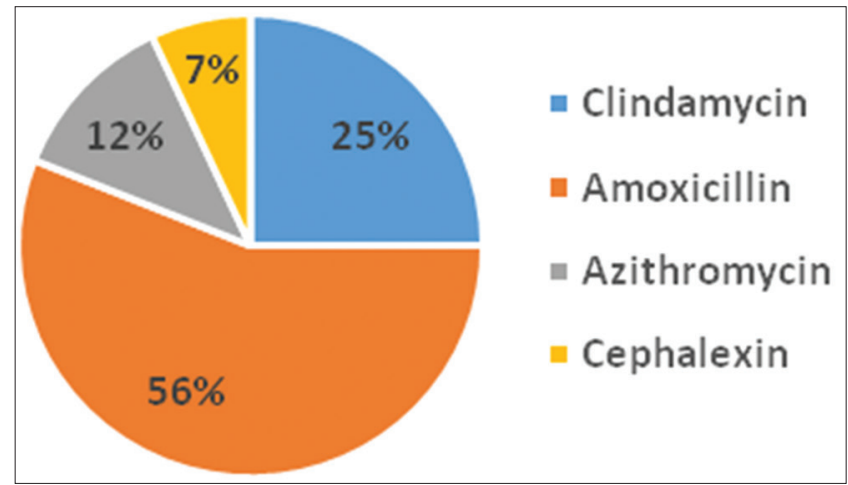

Fig. 8: First-line antibiotic for prevention of bacterial endocarditis of dental students have treated patients with risk of developing IE (Fig. 16).

\section{DISCUSSION}

$\mathrm{BE}$ is serious, life-threatening cardiac disease which accounts for approximately 1 out of 1000 admissions with a range of 0.16-5.4 cases/1000 in a review conducted by 10 large studies [1]. The frequency of $\mathrm{BE}$ has increased in the last two decades, due to increasing age of the population, rising number of patients with prosthetic heart valves, and frequent usage of intravascular devices $[14,15]$. Some cases of $\mathrm{BE}$ also occur after invasive procedures such as dental extraction that are associated with bacteremia. On the other hand, underlying cardiac conditions such as valvular abnormalities can also make the patient susceptible to BE. Keeping these issues, AHA has started giving recommendations for antibiotic prophylaxis and prevention of $\mathrm{BE}$ since 1955. This guideline is recently revised and updated [9] and has been accepted widely.

In the present study, knowledge of 100 undergraduate dental students of the Saveetha Dental College regarding antibiotic prophylaxis for IE was assessed through a questionnaire which contained 16 questions. The questions were framed as per the AHA guidelines. Answering 9 out of 16 questions correctly (56\%) was considered acceptable of which $63 \%$ of the students attained this acceptable level. This is similar to the study by Solomon et al. [1], who showed that $62 \%$ of the participants had an acceptable level of knowledge about antibiotic prophylaxis for the prevention of $\mathrm{BE}$

$73 \%$ of the students were very much aware of IE prophylaxis. About $56 \%$ of the students were aware that the first line of antibiotic for IE prophylaxis is amoxicillin. Nelson and Van Blaricum [16] in a study on 1131 dentists and physicians in the United States concluded that only $39.2 \%$ of them followed the latest AHA guideline while prescribing antibiotics for BE prophylaxis, whereas, in our study, $54 \%$ of students were aware of the latest (2007) AHA guidelines for IE prophylaxis.

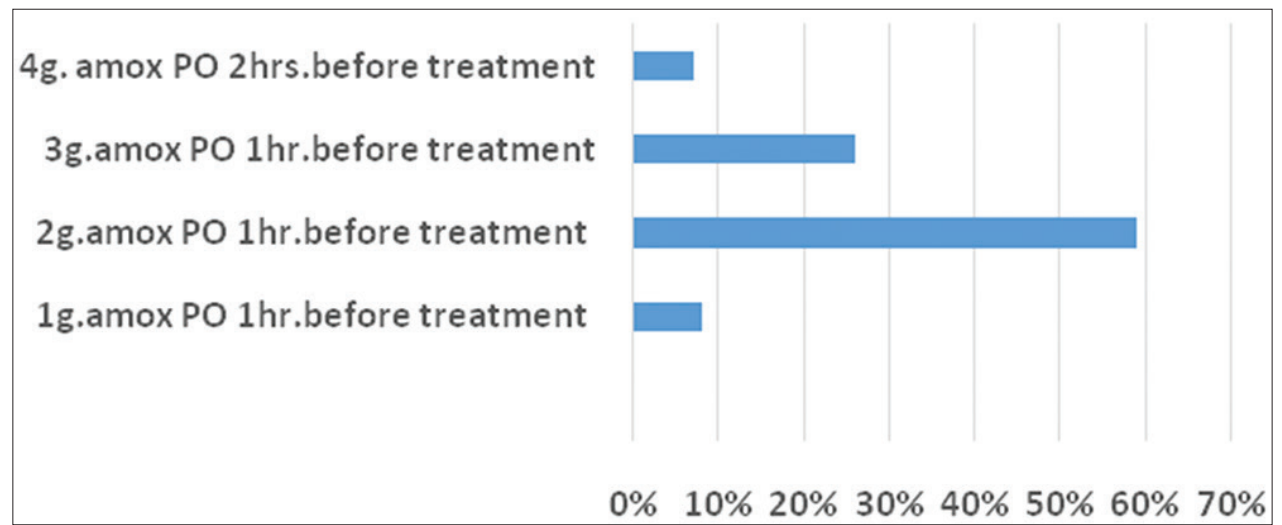

Fig. 9: Recommended regimen for Amoxycillin

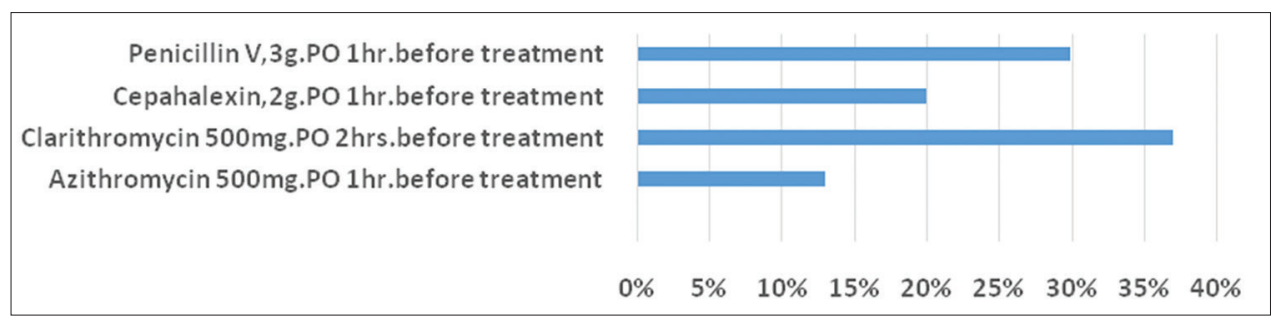

Fig. 10: Antibiotic regimen not recommended for bacterial endocarditis 
In another survey on the method of antibiotic prophylaxis against BE by dentists, Bennis et al [17] found that only $21 \%$ of the dentists used the recommended dose of amoxicillin. In contrary, in our study, $59 \%$ of students prescribed the correct recommended amoxicillin dosage. Tomas Carmona et al. [8] from Spain showed that $45.5 \%$ of the 400 participating dentists would not administer any antibiotic prophylaxis before a tooth extraction in a susceptible patient. Although erythromycin is no longer recommended by AHA for prevention of $\mathrm{BE}, 68.2 \%$ of the participants in this survey opted it to be the antibiotic of first choice in penicillin-allergic patients [8].

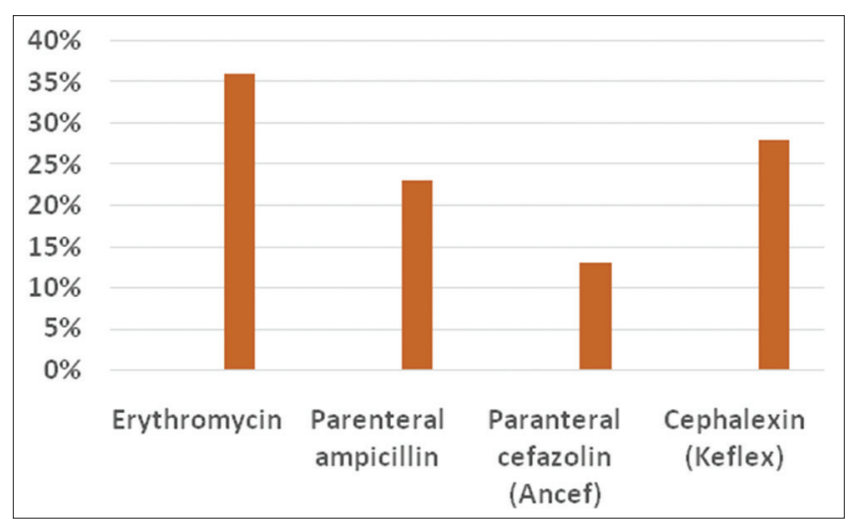

Fig. 11: Antibiotic no longer recommended for prophylaxis

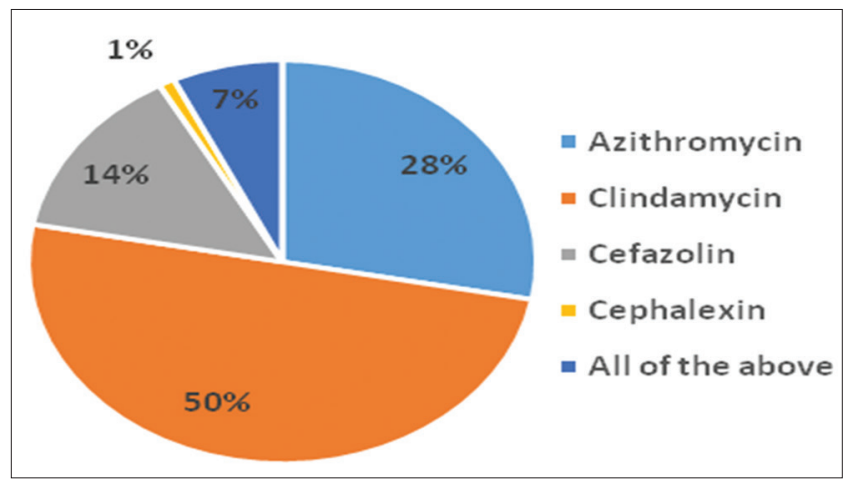

Fig. 12: Antibiotic for penicillin-allergic patients
In our survey, $36 \%$ were aware that erythromycin is no longer recommended by AHA for IE prophylaxis and $50 \%$ of students preferred clindamycin as an alternative drug in penicillin-allergic patients. However, they were unaware about the recommended dosage for clindamycin.

Two-third of students in our study did not have a clear-cut knowledge about the cardiac conditions which require antibiotic prophylaxis during dental treatment. Furthermore, they were not sure about the dental procedures which demand antibiotic prophylaxis for the prevention of IE in susceptible patients. This emphasizes the need for improved education in the teaching curriculum for the students.

Chitsazi and Pourabbas [18], in 2002, found no significant association between age and knowledge in dental procedures requiring prophylaxis; however, there was a significant association between age and knowledge of the latest prophylaxis regimen. $40 \%$ of our dental students have treated patients with risk of developing IE, which shows that they have an acceptable level of experience. Majority, $47 \%$ of participants were aware that effective prophylaxis is possible if the patient is medicated anytime up to $2 \mathrm{hrs}$ from the time of induced bacteremia if in case preoperatively antibiotics were not given.

This study revealed an acceptable level of knowledge about IE among dental students while some were unaware of this condition. Lack of knowledge and awareness regarding IE can be disastrous for the patient and the dentist. Besides theoretical knowledge, practical knowledge about BE should be made available to the students through lectures, handouts, models, auditory, visual, reading, and writing methods [19].

\section{CONCLUSION}

This study revealed a reasonable knowledge about IE prophylaxis among undergraduate dental students but was inadequate. After graduation from dental schools, these students will be subjected to provide dental care including invasive procedures that could potentially lead to the development of $\mathrm{BE}$ in susceptible patients. Hence, this study emphasizes the need for improved education in the teaching curriculum for dental students regarding IE prophylaxis. A standard protocol regarding the training as well as preventive measures for IE should be formulated for the dental students and the knowledge acquired must be transferred into practice.

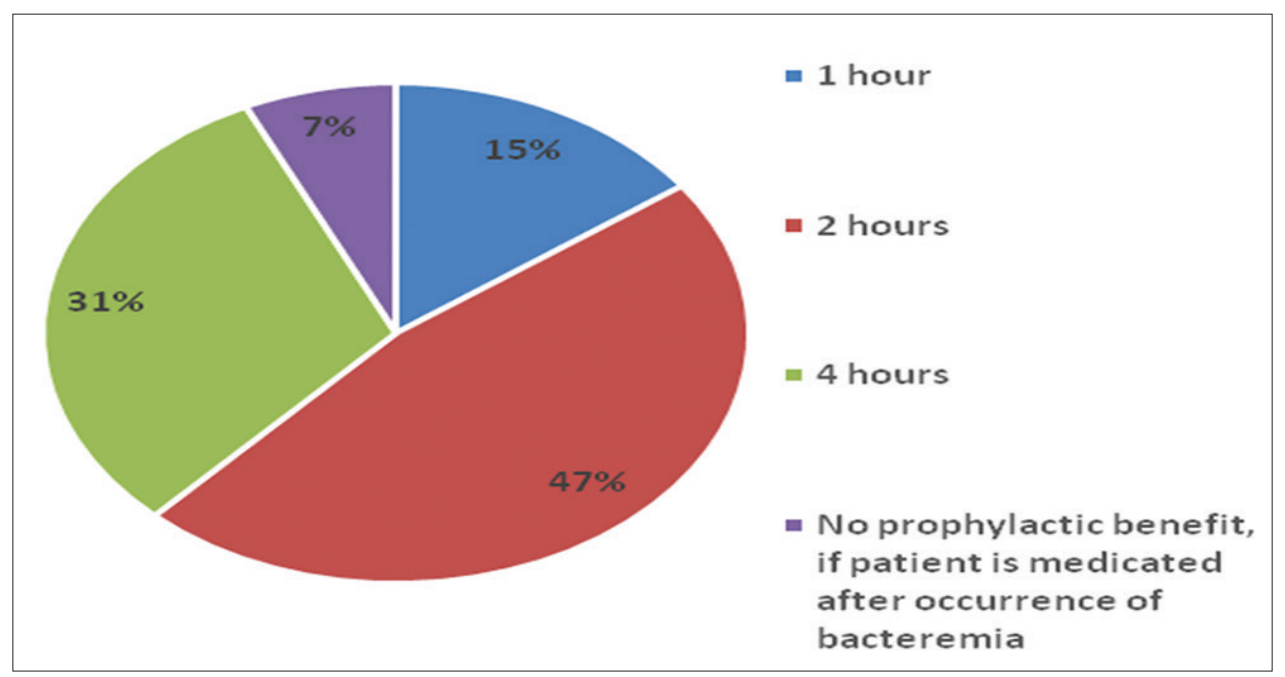

Fig. 13: Effective prophylaxis time after initiation of bacteremia 


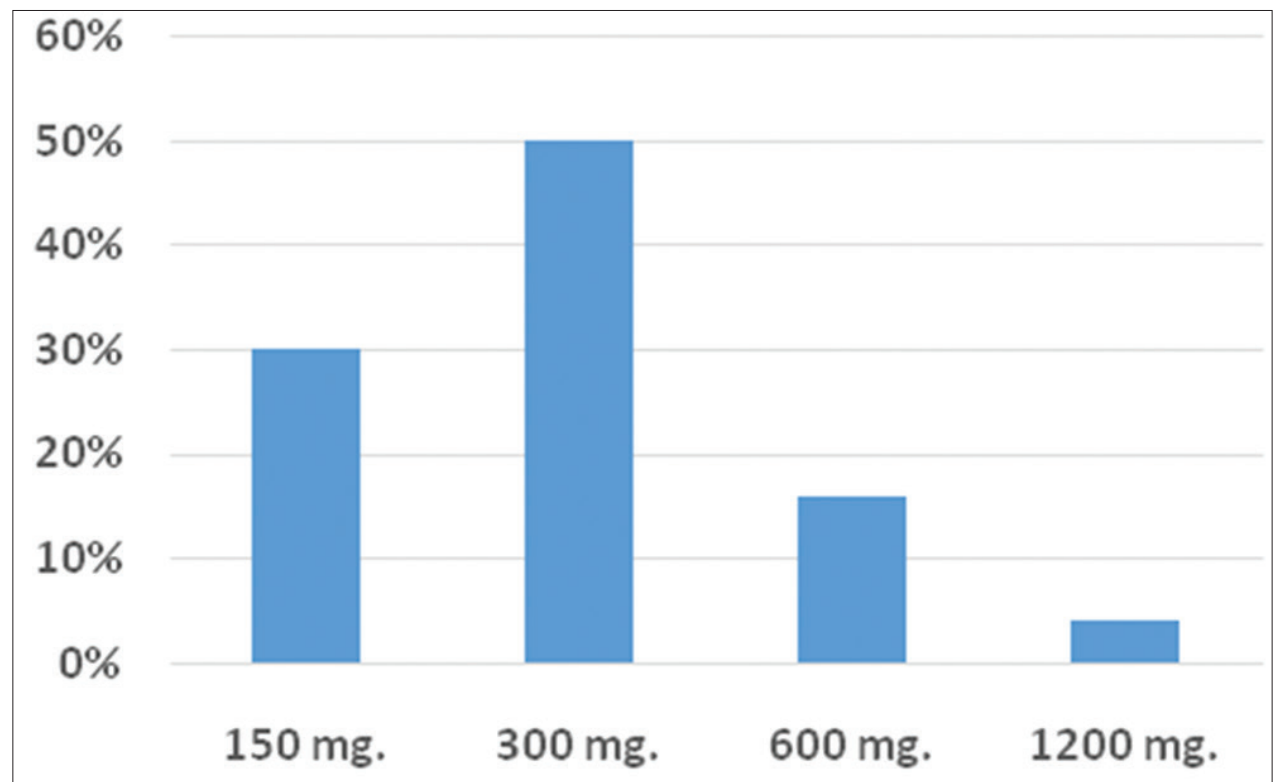

Fig. 14: Recommended dosage of clindamycin

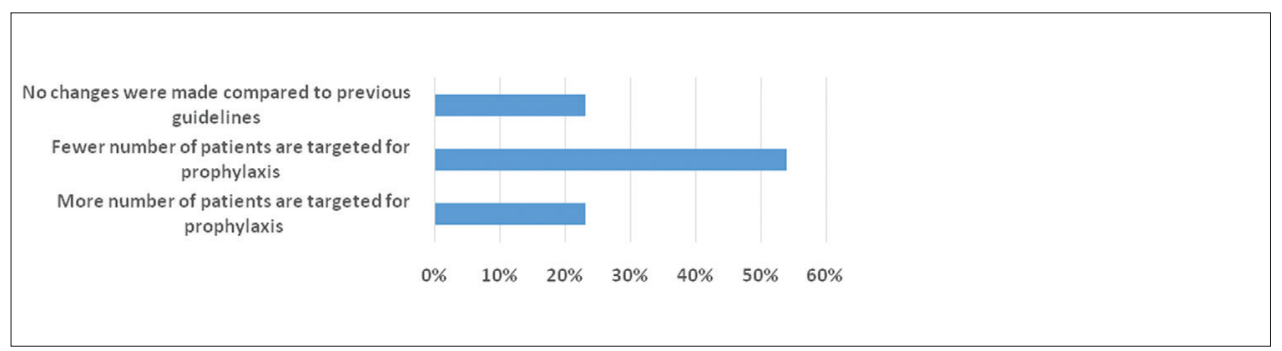

Fig. 15: 2007 American Heart Association guidelines for infective endocarditis prophylaxis

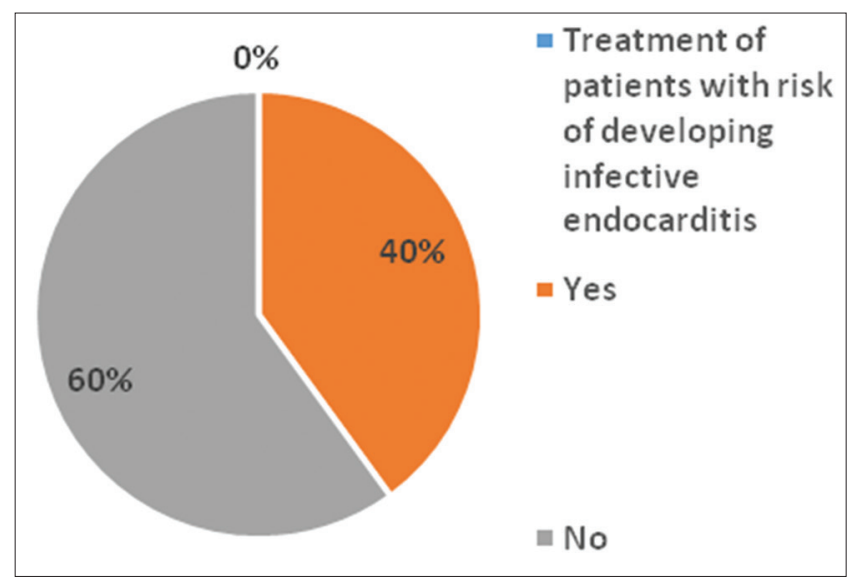

Fig. 16: Treatment of patients with risk of infective endocarditis

\section{REFERENCES}

1. Solomon M, Raveh D, Schlesinger Y, Yinnon AM. Assessment of knowledge of guidelines for the prevention of infective endocarditis amongst clinicians in a teaching hospital. J Hosp Infect 2000;45(4):311-7.

2. Tierney LM, McPhee SJ, Papadakis MA. Current Medical Diagnosis and Treatment 2002. 41 ${ }^{\text {st }}$ ed. New York: Lange/Mc Graw Hill; 2002. p. 1410.

3. Manford M, Matharu J, Farrington K. Infective endocarditis in a district general hospital. J R Soc Med 1992;85(5):262-6.

4. Sandre RM, Shafran SD. Infective endocarditis: Review of 135 cases over 9 years. Clin Infect Dis 1996;22:276-86.
5. Hricak V, Kovacik J, Marx P, Schramekova E, Fischer V, Vitekova D, et al. Etiology and risk factors of 180 cases of native valve endocarditis. Report from a 5-year national prospective survey in Slovak Republic. Diagn Microbiol Infect Dis 1998;31(3):431-5.

6. Sekido M, Takano T, Takayama M, Hayakawa H. Survey of infective endocarditis in the last 10 years: Analysis of clinical, microbiological and therapeutic features. J Cardiol 1999;33(4):209-15.

7. Tomás Carmona I, Diz Dios P, Limeres Posse J, González Quintela A, Martínez Vázquez C, Castro Iglesias A. An update on infective endocarditis of dental origin. J Dent 2002;30(1):37-40.

8. Tomas Carmona I, Diz Dios P, Limeres Posse J, Outumuro Rial M, Caamano Duran F, Fernandez Feijoo J, et al. Pautas de profilaxis antibiotica de endocaditis bacteriana, recommdadas por los odontologos en spana. Med Oral 2004;9:56-62.

9. Dajani AS, Taubert KA, Wilson W, Bolger AF, Bayer A, Ferrieri P, et al. Prevention of bacterial endocarditis. Recommendations by the American heart association. Circulation 1997;96(1):358-66.

10. Brooks SL. Survey of compliance with American Heart Association guidelines for prevention of bacterial endocarditis. J Am Dent Assoc 1980;101(1):41-3.

11. Wagner O, Raz R. Survey of compliance with guidelines for the prevention of infective endocarditis by Israeli dentists. Infect Dis Clin Pract 1997;6:40-6.

12. Scheinfeld N, Struach S, Ross B. Antibiotic prophylaxis guideline awareness and antibiotic prophylaxis use among New York State dermatologic surgeons. Dermatol Surg 2002;28(9):841-4.

13. Adeyemo WL, Oderinu OH, Olojede AC, Ayodele AO, Fashina AA. Nigerian dentists' knowledge of the current guidelines for preventing infective endocarditis. Community Dent Health 2011;28(2):178-81.

14. Watanakunakorn $C$, Burkert $T$. Infective endocarditis at a large community teaching hospital, 1980-1990. A review of 210 episodes. Medicine (Baltimore) 1993;72(2):90-102.

15. Hogevik H, Olaison L, Andersson R, Lindberg J, Alestig K. Epidemiologic aspects of infective endocarditis in an urban 
population. A 5-year prospective study. Medicine (Baltimore) 1995;74(6):324-39.

16. Nelson CL, Van Blaricum CS. Physician and dentist compliance with American Heart Association guidelines for prevention of bacterial endocarditis. J Am Dent Assoc 1989;118(2):169-73.

17. Bennis A, Soulami S, Khadir R, Chraibi N. Survey on the practice of antibiotic prophylaxis of infective endocarditis by dentists. Arch Mal Coeur Vaiss 1996;89(6):713-8.
18. Chitsazi MT, Pourabbas R. Knowledge of dentists who practice in Tabriz regarding the latest prophylaxis regimens for prevention of infective endocarditis. Med J Tabriz Univ Med Sci 2005;64:40-4.

19. Fleming ND. I'm Different, No Dumb: Modes of Presentation (VARK) in the Tertiary Classroom. In Zelmer A, editor. Research and Development in Higher Education: Proceeding of the 1995 Annual Conference of the Higher Education and Research Development Society of Australia (HERDSA). 1995. p. 308-13.

\section{ANNEXURE 1: QUESTIONNAIRE}

1. Are you aware of infective endocarditis prophylaxis?
(a) Yes
(b) No.

2. While taking patients' medical history do you assess the risk factors for infective endocarditis?
(a) Yes
(b) No.

3. The following are the organisms implicated with bacterial endocarditis except:
(a) Streptococcus viridans
(b) Staphylococcus aureus
(c) Enterococcus
(d) Actinobacillus actinomycetemcomitans.

4. Bacterial endocarditis is more likely to occur following transient bacteremia induced by:
(a) Dental extraction
(b) Periodontal surgery

(c) Scaling

(d) Daily activities such as chewing food and carrying out oral hygiene.

5. The bacteremia which results from invasive dental procedures is from
(a) 10 to 15 minutes
(b) 1 to 2 hrs
(c) 3 to 4 hrs
(d) 5 to 6 hrs.

6. Prophylaxis against infective endocarditis is indicated in patients with following conditions except:
(a) Prosthetic cardiac valves
(b) Ventricular septal defects
(c) Cardiac transplant recipients with cardiac valvuloplasty
(d) Unrepaired cyanotic congenital heart disease.

7. Dental procedures which require antibiotic prophylaxis includes all of the following except:
(a) Routine anesthetic injection through non-infected tissue
(b) Tooth extraction
(c) Suture removal
(d) Scaling and root planing of teeth.

8. The first-line antibiotic for prevention of bacterial endocarditis in dental practice is:
(a) Clindamycin
(b) Amoxicillin
(c) Azithromycin
(d) Cephalexin.

9. The recommended regimen for antibiotic prophylaxis using amoxicillin is:

(a) $1 \mathrm{~g}$ of amoxicillin PO $2 \mathrm{hrs}$ before the appointment (b) $2 \mathrm{~g}$ of amoxicillin PO $1 \mathrm{hr}$ before the appointment

(c) $3 \mathrm{~g}$ of amoxicillin PO $1 \mathrm{hr}$ before the appointment

(d) $4 \mathrm{~g}$ of amoxicillin PO 2 hrs before the appointment.

10. Which of the following regimens is not recommended for antibiotic prophylaxis in susceptible patients?

(a) Azithromycin, $500 \mathrm{mg}$ PO, $1 \mathrm{hr}$ before treatment

(b) Clarithromycin, $500 \mathrm{mg}$ PO, 2 hrs before treatment

(c) Cephalexin, 2 g PO, 1 hr before treatment

(d) Penicillin V, 3 g PO, 1 hr before treatment.

11. Which of the following antibiotics is no longer recommended by the American Heart Association for prevention of bacterial endocarditis?
(a) Erythromycin
(b) Parenteral ampicillin
(c) Parenteral cefazolin (Ancef)
(d) Cephalexin (Keflex).

12. If a patient is allergic to penicillin which of the following drugs can be given for antibiotic prophylaxis?

(a) Azithromycin

(b) Clindamycin

(c) Cefazolin

(d) Cephalexin

(e) All of the above.

13. If antibiotics are not given before the procedure, in such a case, effective prophylaxis is possible if the patient is medicated anytime up to ...... from the time of induced bacteremia.
(a) $1 \mathrm{hr}$
(b) 2 hrs
(c) 4 hrs
(a) $150 \mathrm{mg}$
(b) $300 \mathrm{mg}$
(c) $600 \mathrm{mg}$
(d) $1200 \mathrm{mg}$

(d) There is no prophylactic benefit if the patient is medicated after occurrence of bacteremia.

14. What is the clindamycin dose in the most recent set of recommendation for prevention of bacterial endocarditis?

15. In the 2007 American Heart Association guidelines for infective endocarditis prophylaxis,

(a) More number of patients are targeted for prophylaxis

(b) Fewer number of patients are targeted for prophylaxis

(c) No changes were made compared to previous guidelines.

16. Have you treated any patient with risk of developing infective endocarditis?

(a) Yes

(b) No. 